\title{
O turismo como alternativa para recuperação de áreas degradadas pela mineração
}

\section{The tourism as alternative for recovery of degraded areas for mining}

\author{
Emanuela Mansur Soares (SOARES, E. M.) ${ }^{*} \mathrm{e}$ \\ Mariana Faria Thomé da Silva (SILVA, M. F. T. da) ${ }^{* *}$
}

\begin{abstract}
RESUMO - O grande incremento na produção minerária provoca interferências no meio ambiente promovendo a supressão da vegetação, alterando drasticamente a paisagem e perturbando totalmente o ecossistema. A recuperação dessas áreas é uma exigência da legislação ambiental vigente que é discutida neste artigo a partir de uma revisão bibliográfica. Este estudo aborda como tema as diversas formas de recuperação de áreas ambientalmente danificadas pela mineração, como, por exemplo, as técnicas de manejo de espécies nativas e, demonstra também, como principal objetivo deste artigo, que a atividade turística é uma ótima alternativa para recuperação dessas áreas. Concluise que o turismo pode reverter o quadro de desvalorização ambiental e comercial da região degradada, melhorando a qualidade de vida da comunidade do entorno, gerando novos empregos e agregando valor cultural para a localidade.
\end{abstract}

Palavras-chave: Mineração; Áreas degradadas; Turismo.

ABSTRACT - The great increment in the production mining would provoke interferences in the environment drastically promoting the suppression of the vegetation, modifying the landscape and disturbing the ecosystem totally. The recovery of those areas is a demand of the effective environmental legislation that it is discussed in this article starting from a revision bibliographical. This study approaches as theme the several forms of recovery of areas environmental damaged for the mining, as, for instance, the techniques of handling of native species and, it also demonstrates, as main objective of this article, that the tourist activities is a great alternative for recovery of those areas. It is ended that the tourism can change the picture of environmental and commercial depreciation of the degraded area, improving the quality of the communities, generating new jobs and joining cultural value to the place.

Key words: Mining; Degraded areas; Tourism.

\footnotetext{
* Bacharel em Biologia pela Pontifícia Universidade de Minas Gerais. Mestranda em Turismo e MeioAmbiente do Centro Universitário UNA. Endereço: Rua Aimorés, 1451 (Lourdes). CEP: 30140-071 Belo Horizonte - MG (Brasil). Telefones: (31) 9995-0360.E-mail: emanuelamansur@uol.com.br

Bacharel em Turismo pelo Centro Universitário Newton Paiva. Mestranda em Turismo e Meio Ambiente do Centro Universitário UNA. Endereço: Rua Bernardo Guimarães, 2440, ap. 300 (Lourdes). CEP: 30140-082 - Belo Horizonte - MG (Brasil). Telefone: (31) 8812-3548. E-mail: marianafthome@yahoo.com.br
} 


\section{INTRODUÇÃO}

O rápido crescimento da população mundial levou à necessidade de grandes incrementos da produção minerária, os quais vêm sendo obtidos através da aplicação intensiva de novas tecnologias (KOPEZINSKI, 2000). A mineração é um dos setores básicos da economia do Brasil, contribuindo de forma decisiva para o bem estar e a melhoria da qualidade de vida das presentes e futuras gerações, pois, a partir da produção minerária criam-se empregos e insumos para a indústria em geral.

Contudo, tem-se observado efeitos negativos, principalmente com a degradação dos ecossistemas, até então estáveis e harmônicos. A atividade minerária deriva dos primórdios, quando o homem pré-histórico descobriu o valor do minério e passou a utilizá-lo de forma constante, seja para fabricar material para seu trabalho ou como material de construção. Desde então a exploração destes recursos vem produzindo sua escassez, já que uma das características dos recursos minerais é que estes tendem a acabar, ou seja, não se renovam.

Diante desta problemática, o presente estudo visa contribuir para a discussão que gira em torno da degradação do solo e da paisagem em áreas de mineração e a sua recuperação através da atividade turística. O Turismo nestas áreas pode estimular a economia e incentivar o uso e a reutilização de áreas naturais que foram prejudicadas de alguma forma por atividades antrópicas. Sob este cenário, é possível agregar novamente valor econômico, social e cultural nestes locais melhorando a qualidade de vida da comunidade do entorno e da sociedade, sem deixar de usufruir da mineração, já que esta constitui papel de grande importância para a sociedade.

Segundo Wagner et al. (2002), o setor mineral, em 2000, representou 8,5\% do Produto Interno Bruto (PIB) do Brasil, ou seja: US\$ 50,5 bilhões de dólares, gerou 500.000 empregos diretos e um saldo na balança comercial de US\$ 7,7 bilhões de dólares, além de ter tido um crescimento médio anual de 8,2\% no período 1995/2000. Todavia, esta atividade também representa um grave problema nacional, pois através da mineração surgem problemas ambientais tais como a erosão do solo, assoreamento, poluição, dentre outros.

Em Minas Gerais (MG) a mineração continua sendo a mais importante atividade econômica. Para se ter uma idéia, basta citar que a indústria mineral responde por mais de $50 \%$ das exportações do Estado, além de gerar cerca de 130 mil empregos diretos em 
suas mais diversas regiões, de acordo com dados do Sindicato da Indústria Mineral do Estado de Minas Gerais (SINDIEXTRA, 2007). Segundo o Instituto Brasileiro de Mineração - IBRAM (2008), Minas Gerais responde por 35\% da produção minerária brasileira, sendo o maior produtor de Ferro (das 350 milhões de toneladas produzidas no Brasil em 2007, 70\% saíram de MG), Fosfato, Ouro, Tantalita e Zinco, além de ser o maior produtor de Nióbio do mundo.

Apesar dos efeitos econômicos que a atividade minerária obtém, tem-se que levar em consideração que a atividade possui duas características principais. A primeira decorre da própria jazida a ser lavrada que além de ser um bem não-renovável, produz interferências marcantes e inevitáveis no meio ambiente. A segunda é quanto aos minérios extraídos que correspondem ao seu produto, os quais são indispensáveis à humanidade.

Segundo Fonseca (1989) essa atividade constitui um dos principais fatores antrópicos de degradação ambiental, devido às grandes modificações físicas e bióticas que provoca. No âmbito do turismo, o meio ambiente preservado é fundamental para o desenvolvimento da atividade. A degradação que a mineração provoca na paisagem de cidades turísticas torna-se fator determinante da atividade, pois pode provocar quedas drásticas no que diz respeito à demanda turística daquele local. Faz-se necessário, que cidades como Diamantina, Ouro Preto, Itabira, Governador Valadares, dentre outras que possuem áreas de mineração, principalmente no que diz respeito às gemas, invistam em pesquisas e no controle paisagístico da região para que não ocorra nenhuma influência negativa no turismo local.

Os efeitos desses processos modificadores no meio ambiente são promovidos em escalas pontuais até escalas regionais, promovendo a supressão da vegetação, alterando drasticamente a paisagem e perturbando totalmente o ecossistema (GARDNER, 2001). De acordo com Sobreira e Fonseca (2001), a necessidade de criação de novas áreas urbanas em função do crescimento da população, a partir dos anos sessenta não foi acompanhada por planejamento prévio adequado, levando à ocupação de áreas onde se desenvolveram atividades de mineração no passado. Na maioria das vezes essas áreas apresentam características morfológicas e geotécnicas desfavoráveis, gerando, assim, um quadro problemático no que se refere à segurança da população e das estruturas 
presentes nessas áreas, podendo estimular desmoronamentos e crateras de diversos níveis.

Gomide (1994) relata que, no Brasil, a preocupação acerca da manutenção e recuperação do meio ambiente teve início em 1988 após a inserção na Constituição Nacional, do Decreto Federal 97.632 de 10/04/89, que veio formalizar a obrigatoriedade da adoção de PRAD’s (Planos de Recuperação de Áreas Degradadas).

Segundo consta em Bursztyn (1994) o primeiro dispositivo legal, visando a minimizar os impactos negativos causados por mineração, foi a Lei n. 6.938, de 1981, que, através do Decreto Federal n. 88.351, instituiu o Licenciamento Prévio (LP), expedido na fase preliminar do planejamento da atividade, observando os planos municipais, estaduais e federais de uso e ocupação do solo; o Licenciamento de Instalação (LI), que é expedido baseado no projeto executivo final, autorizando o início da atividade; e o Licenciamento de Operação (LO), que é expedido após vistorias e que autoriza, depois de ocorridas às verificações, o início da atividade segundo previsto nos LP e LI. A partir de 1986, com a Resolução n. 1 do Conselho Nacional do Meio Ambiente - CONAMA estabeleceram-se as definições, as responsabilidades, os critérios básicos e as diretrizes gerais para o uso e implementação da Avaliação de Impactos Ambientais (AIA) como instrumento da Política Nacional do Meio Ambiente.

Ainda segundo Bursztyn (1994), o Decreto definiu também, em seu artigo $1^{\circ}$, que os empreendimentos que se destinam à exploração dos recursos minerais deverão submeter seus projetos à aprovação dos órgãos federais, estaduais e municipais competentes e executar o Estudo de Impacto Ambiental (EIA), que deverá ser executado por profissionais de várias áreas para que se possa entender profundamente sobre a atividade que irá se iniciar e compreender totalmente o ambiente que será afetado. Além deste, deverão executar também, o Relatório de Impacto Ambiental, que aborda e esclarece todos os elementos do objeto que se está estudando para que possa ser analisado por qualquer interessado, trazendo estudos técnicos e científicos que foram realizados sobre o impacto ambiental da área e, o Plano de Recuperação de Áreas Degradadas, que deverá ser previamente elaborado e aprovado por órgão do governo.

Segundo Dutra et al. (2005) é fácil perceber atualmente, a perturbação que o homem causa ao destruir um ecossistema, interrompendo o equilíbrio biológico que é formado por uma complexa interação entre as comunidades vegetais, animais e 
principalmente o solo. De acordo com Balensiefer (1998) são consideradas áreas degradadas, extensões naturais que perderam a capacidade de recuperação natural após sofrerem distúrbios. A degradação é um processo induzido pelo homem ou por acidente natural que diminui a atual e futura capacidade produtiva do ecossistema.

Já a recuperação dessas áreas, conforme o Instituto Brasileiro do Meio Ambiente e dos Recursos Naturais Renováveis - IBAMA (1990) pode ser definida como um processo de reversão de tais áreas em terras produtivas e auto-sustentáveis, de acordo com uma proposta preestabelecida de uso do solo podendo chegar ao nível de uma recuperação de processos biológicos - sendo assim chamada "reabilitação" -, ou mesmo aproximar-se muito da estrutura ecológica original - "restauração".

As áreas mineradas podem ser recuperadas para atividades turísticas, agropecuárias, florestais, recreativas, bem como para a conservação da flora e fauna silvestres (GRIFFITH, 1981). No entanto, a recuperação natural dessas áreas é, em geral, muito lenta. Em alguns casos, o processo de degradação agrava-se com a intensificação da erosão e aparecimento de voçorocas (LEITE, 1992).

\section{RECUPERAÇÃO DE ÁREAS DEGRADADAS}

Um aspecto fundamental na recuperação de áreas degradadas pela mineração é o conhecimento do solo ou do substrato destacando especialmente suas propriedades físicas, químicas, biológicas e mineralógicas que deverão apresentar condições adequadas para o desenvolvimento das plantas (FONTES, 1991). Gomes-Pompa e Wiechers (1979) apontam os estudos sobre solos como ponto relevante para a regeneração dos ecossistemas tropicais e subtropicais, devendo ser considerados para o melhor entendimento e planejamento dos processos ecológicos. Pode-se definir que a qualidade do solo é a capacidade de funcionar dentro dos limites do ecossistema; sustentar a produtividade biológica; manter a qualidade ambiental e promover a saúde vegetal e animal (DORAN et al., 1996).

Porém, os substratos de áreas degradadas pela mineração comumente apresentam características de retenção de água, fertilidade e atividade biológica inadequados ao crescimento vegetal (BARTH, 1989; IBAMA, 1990). Assim, o sucesso 
da recuperação pode depender da vegetação, através da acumulação de biomassa e da ciclagem dos nutrientes contidos nesta (SILVA, 1994), atuando como um componente ativo na formação do solo e exercendo efeitos químicos, físicos e biológicos que contribuem para o aumento dos níveis de nutrientes (ROSADO et al., 1996).

A recuperação de solos minerados é uma exigência da legislação ambiental brasileira vigente, sendo apontada como uma das ações necessárias à racionalização do uso da terra e melhoria da qualidade ambiental (UNCED, 1991). A principal ação para que as áreas degradadas possam voltar a ser produtivas após o manejo do solo, consistem na revegetação do local de maneira inclusive, a propiciar o retorno da fauna, em especial de polinizadores e dispersores (MOREIRA, 2004). A revegetação é parte essencial no processo de recuperação dessas áreas, a qual implica, não só o plantio de espécies vegetais, mas também uma seleção adequada dessas espécies e das técnicas de manejo, visando à aceleração e a reconstituição dos processos de sucessão que acontecem naturalmente (DUTRA, 2002).

Davide (1994) comenta que a escolha de espécies para utilização em recuperação de áreas degradadas deve ter como ponto de partida estudos de composição florística da vegetação remanescente da região. Para tanto, a maioria dos programas desta natureza tem dado especial atenção ao uso de espécies nativas da própria região na recomposição da cobertura vegetal, visando garantir a regularização de recursos hídricos, a conservação de espécies vegetais e animais, bem como a manutenção da diversidade genética das espécies, conforme Companhia Energética de São Paulo CESP (1992).

Outras práticas importantes são as incorporações de matéria orgânica, as fertilizações e as irrigações. A primeira pode ser feita com uso de esterco animal, resíduos de plantas, bagaço de cana, casca de arroz ou outras fontes. A presença destes materiais pode facilitar processos microbianos como a humificação, agregação do solo e ciclagem de nitrogênio, essenciais ao estabelecimento da vegetação nos estéreis (substâncias naturais não-aproveitáveis economicamente) e rejeitos de mineração (SEAKER; SOPPER, 1988).

A escolha ou criação de um modelo de revegetação é um processo em constante aprimoramento, que é alimentado não só pelos conhecimentos básicos sobre ecologia, demografia, genética, biogeografia, mas também pelas informações sobre o ambiente 
físico e biológico da região onde irá ser implantado. A interação dos conhecimentos teóricos básicos, informações sobre a área e tecnologia disponível é que vai determinar qual o modelo mais adequado para cada situação (KAGEYAMA; GANDARA, 2001).

Em se tratando da recuperação de áreas degradadas pela mineração para a utilização direta pelo homem, Povidelo e Neto (2006) citam exemplos da reabilitação destas áreas devido à atividade turística, como ocorrido na Alemanha, onde antigas minas de carvão, na região do vale do Rühr, foram convertidas em museus onde é possível observar todo o contexto histórico da exploração, adquirindo assim um valor turístico e outro histórico-cultural. No Brasil também são verificadas situações exemplares, como a Pedreira Paulo Leminsky (Ópera de Arame) em Curitiba (PR), a Pedreira do Chapadão em Campinas (SP), antiga extração de diabásio bastante utilizada para eventos de grande porte e o Parque do Varvito em Itu (SP), transformado em parque em função de seu destacado valor geológico e educativo.

$\mathrm{Na}$ atual conjuntura econômica em que se vive tanto à área de exploração mineral quanto a recuperação de áreas degradadas encontra-se em fase de grande prosperidade tecnológica no país, principalmente no tocante às medidas de reabilitação destas últimas. No entanto as relações das atividades deste setor industrial com o meio ambiente devem ser mais bem avaliadas no que envolve a aplicabilidade da gestão ambiental em mineradoras de Minas Geras, destacando as razões, os benefícios e as restrições legais. É preciso também, que gestores da atividade turística, representantes da atividade, estudantes e faculdades façam projetos voltados para a recuperação destas áreas e entrem em acordo com as mineradoras e municípios para que ocorra um efetivo empenho de todos os envolvidos.

Em função do avanço das leis que disciplinam a ação humana sobre as florestas de proteção e a crescente conscientização sobre a importância da preservação ambiental (NAPPO et al., 1999), muitas empresas tiveram que adequar seus processos industriais, para desenvolver e implantar sistemas de gestão ambiental em seus processos (HERMANNS, 2005). Neste sistema, empresários começaram a verificar que uma postura ambientalmente correta na gestão dos processos refletia-se diretamente na produtividade, qualidade e conseqüentemente, em melhores resultados econômicofinanceiros (GUTBERLET, 1996). 
O presente trabalho tem por objetivo efetuar o levantamento de informações básicas sobre a recuperação de áreas mineradas que possam orientar ações de restabelecimento das mesmas, verificando a potencialidade de reutilização e integrar esta potencialidade à atividade turística.

\section{ANÁLISE}

O conceito de degradação tem sido geralmente associado aos efeitos ambientais considerados negativos e que decorrem, principalmente, de atividades ou intervenções humanas. Willians et al. (1990) definem que degradação acontece a partir da destruição, remoção ou expulsão da vegetação nativa e da fauna, quando a camada fértil do solo for removida, enterrada ou for perdida e, por fim, quando a qualidade e o regime de vazão do sistema hídrico estiverem alterados. Os mesmos autores ainda afirmam que, a degradação ambiental ocorre quando o desenvolvimento socioeconômico do local já está inviabilizado e quando há perda de adaptação às características físicas, químicas e biológicas do solo onde ocorreu o dano.

Os impactos ambientais negativos inerentes à implantação de uma atividade minerária levam ao estudo de medidas que visam atenuá-los ou eliminá-los durante a exploração. São as chamadas medidas mitigadoras. Quando os impactos não podem ser evitados e não são passíveis de atenuações devem ser propostas as medidas compensatórias (DIAS, 2001).

Para Willians et al., (1990), a recuperação de áreas degradadas significa que o local degradado será recuperado e reutilizado segundo um plano preestabelecido para o uso do solo, além de possuir condições mínimas de estabelecer um novo equilíbrio objetivando o desenvolvimento de um novo solo e uma nova paisagem.

A degradação do solo e da paisagem são fatores que interferem diretamente no turismo de uma região já que afastam os turistas. De acordo com Ruschmann (2005), a inter-relação entre o turismo e o meio ambiente é incontestável, uma vez que este último constitui a "matéria-prima" da atividade.

O patrimônio natural que determinada região possui, como por exemplo, de montanhas, cachoeiras, cavernas e grutas, apresenta-se também como atrativo turístico 
já que este patrimônio é um grande motivador da demanda turística. Sendo assim, a paisagem torna-se elemento fundamental da atividade tornando-se essencial para o seu desenvolvimento.

Constata-se então, que para os empresários, o termo gestão ambiental pode se atribuir a um objetivo maior, que é a busca permanente de melhoria da qualidade ambiental dos serviços, dos produtos e do ambiente de trabalho de qualquer organização (HERMANNS, 2005). As organizações estão percebendo que a sua função não é meramente econômica e ganha espectros de responsabilidade social.

Considera-se, então, que atuar de maneira ambientalmente responsável é um diferencial entre as empresas. Em breve, este diferencial se tornará um pré-requisito, e quanto antes, as empresas perceberem esta nova realidade, maior será a chance de se manterem no mercado (GUTBERLET, 1996).

No âmbito da atividade turística, "desenvolvimento" e "preservação" do meio ambiente devem ocorrer ao mesmo tempo, a partir do ponto em que se deve pensar no espaço como um objeto de uso e de renda tanto para as empresas que promovem o turismo, quanto para os lugares receptores dessa atividade. O turismo, quando bem planejado e organizado, contribui para um desenvolvimento sustentável que promoverá um processo de transformação no qual a exploração dos recursos, a direção dos investimentos, a orientação do desenvolvimento tecnológico e a mudança institucional se harmonizam e reforçam o potencial presente e futuro, a fim de atender às necessidades e aspirações humanas (MAGALHÃES, 2002).

O turismo tem a capacidade de melhorar o meio ambiente, gerar fundos para a conservação, preservar a cultura e a história e proteger atrações naturais. É necessário adotar estratégias globais que visem a um aprimoramento técnico-científico, educacional e do desenvolvimento econômico-social (incluindo-se as atividades turísticas), tendo em vista os interesses maiores das populações envolvidas, quais sejam: a melhoria geral da qualidade de vida e a recuperação e a preservação da natureza.

A partir de um maior planejamento e, consequientemente, um uso mais racional dos recursos naturais pelas empresas e instituições do setor turístico e, concomitantemente a isso, esclarecer as populações sobre as questões que envolvem "o turismo, o meio ambiente e a comunidade", obter-se-á caminhos que permitam, de um lado, o desenvolvimento econômico e social e, de outro, o aproveitamento racional dos 
recursos naturais com vistas à preservação e recuperação do ambiente como um todo. Pode-se concluir, a partir do exposto, que a prática do turismo passa pela percepção da sustentabilidade e da proteção dos recursos naturais (MAGALHÃES, 2002). Portanto, deve-se utilizar dessa prática sustentável que é a atividade turística e aproveitá-la para transformar áreas danificadas pela mineração em verdadeiros centros turísticos e culturais e, ao mesmo tempo, incentivar práticas sustentáveis de reutilização e aproveitamento do solo.

De acordo com Dias (2003), o território é um elemento básico do desenvolvimento turístico, pois abriga os recursos ambientais e culturais dos destinos turísticos. Para evitar os danos ambientais é preciso que seja feito um manejo adequado da exploração dos recursos naturais, bem como das outras atividades econômicas desenvolvidas na superfície terrestre. Esse manejo está relacionado ao planejamento do uso da terra, que deve seguir certas regras básicas, prevenindo danos, ou pelo menos os minimizando.

Antes que qualquer atividade seja realizada deve ser feito um diagnóstico da área, devendo-se prever os impactos ambientais que possam acontecer (KELLER, 1996). Por isso, devem ser feitas uma avaliação e uma perícia ambiental, observando os agentes e processos causadores das interferências, das degradações e dos danos ambientais responsáveis por desgastar e exaurir os recursos naturais essenciais à qualidade ambiental para as populações. Sendo assim, é preciso ficar atento para que futuras instalações turísticas a serem construídas em áreas degradadas pela mineração não as danifiquem ainda mais.

Segundo Magalhães (2002), o discurso da sustentabilidade e do desenvolvimento, se orienta no sentido da necessidade de tratá-lo de uma perspectiva multidimensional que articula os aspectos econômicos, políticos, éticos, sociais, culturais e ecológicos, evitando o reducionismo do passado.

Então, quando há a combinação do desenvolvimento, tanto ambiental quanto o econômico, em prol de um "capitalismo verde" e a prudência ecológica, o uso racional de recursos naturais e a justiça social, por meio da cooperação e do multilateralismo para enfrentar os desafios presentes, chegar-se-á a um crescimento econômico e ao mesmo tempo à conservação dos recursos para a manutenção da espécie humana (MAGAlHÃES, 2002). Segundo Ross (2000), é preciso encontrar instrumentos 
político-administrativos que possibilitem o desenvolvimento das sociedades e recuperem e preservem os recursos naturais. Isso, devido ao fato que é praticamente impossível para a sociedade atual privar-se do uso de recursos naturais e minerais, pois foram os múltiplos usos desses recursos que possibilitaram o grande desenvolvimento dos últimos séculos.

\section{CONCLUSÃO}

A mineração é uma atividade indispensável à humanidade, tanto quanto aos bens que produz, quanto aos empregos que gera, sejam eles diretos ou indiretos. Vários municípios com grande potencial turístico, como por exemplo, Mariana, Ouro Preto, Ipatinga, Nova Era, Guanhães, dentre outros, têm a mineração como importante atividade econômica, e, o que vem ocorrendo com a degradação do solo e da paisagem, interfere drasticamente na qualidade de vida da população e na atividade turística.

Se a mineração não for bem planejada, pode ocorrer um uso indevido dos recursos hídricos da região, gerando poluição e comprometendo a qualidade de vida dos trabalhadores e da comunidade. Quanto ao turismo, se a paisagem for muito afetada e os municípios não souberem reverter este quadro, a demanda turística poderá diminuir comprometendo a economia da região. Como exemplo de boa utilização deste fato, temse a cidade de Mariana, que possui a Mina de Ouro da Passagem, servindo como um expressivo atrativo turístico local.

Sendo assim, é fato que ocorra a degradação ambiental e paisagística por parte da mineração. Para tanto, existem as leis que disciplinam o uso e ocupação do solo e a implementação dos planos de recuperação de áreas degradadas, na tentativa de minimizar os impactos ao meio ambiente. As leis têm que ser cumpridas para que, além de sustentabilidade ambiental das áreas, possam ser reutilizadas para fins turísticos já que, neste caso, o turismo pode transformar-se em grande fonte alternativa de renda e emprego para a população das áreas mineradas.

A reutilização destas áreas degradadas pela mineração para fins turísticos pode ocorrer com a transformação das áreas em parques temáticos, museus, espaços para educação ambiental, ou, até mesmo, utilizando as cavas como atrativo turístico. 
Portanto, para que tudo isso possa ser realmente implementado, faz-se necessário que as empresas responsáveis pela mineração, unam-se às empresas de interesse turístico, juntamente ao poder público, e desempenhem papel fundamental na recuperação das mesmas.

\section{REFERÊNCIAS}

BALENSIEFER, M. Estado da arte em recuperação e manejo de áreas frágeis e/ou degradadas. In: WORKSHOP RECUPERAÇÃ̃O E MANEJO DE ÁREAS DEGRADADAS, 1998, Campinas, Memória... Jaguariúna: EMBRAPA, CNPMA, 1998, p. 15-18. (EMBRAPA - CNPMA. Documentos, 13).

BARTH, R. C. Avaliação da recuperação de áreas mineradas no Brasil. Viçosa: UFV, 1989. 41 p. (Boletim Técnico SIF, 1).

BURSZTYN, M. M. A. Gestão ambiental: instrumentos e práticas. Brasília: Editora do IBAMA, 1994. 172 p.

COMPANHIA ENERGÉTICA DE SÃO PAULO (CESP). Recomposição de matas nativas pela CESP. São Paulo-SP, 1992. 13 p.

DAVIDE, A. C. Seleção de espécies vegetais para recuperação de áreas degradadas. In: SIMPÓSIO NACIONAL DE RECUPERAÇÃO DE ÁREAS DEGRADADAS, 2, 1994, Foz do Iguaçu. Anais... Curitiba: FUPEF, 1994. p. 111-122.

DIAS, E. G. C. S. Avaliação de impacto ambiental de projetos de mineração no Estado de São Paulo: a etapa de acompanhamento. São Paulo, 2001. 283 p. Tese (Doutorado) - Escola Politécnica, Universidade de São Paulo.

DIAS, R. Planejamento do turismo: política e desenvolvimento do turismo no Brasil. São Paulo: Editora Atlas S. A., 2003.

DORAN, J. W.; SARRANTONIO, M.; LIEBIG, M. A. Soil health and sustainability. Advances in Agronomy, San Diego, v. 56, p. 1-54, 1996.

DUTRA, G. C.; BOTELHO, S. A.; FEREIRA, C. A. G.; DAVIDE, A. C. Avaliação do crescimento de espécies arbóreas plantadas em duas estratégias de recuperação de áreas degradadas pela mineração. In: SIMPÓSIO NACIONAL DE RECUPERAÇÃO DE ÁREAS DEGRADADAS, 5., 2002, Belo Horizonte. Anais... Belo Horizonte, 2002, p. 331-33.

Avaliação do crescimento de espécies arbóreas plantadas em duas estratégias de recuperação de áreas degradadas pela mineração. 2005. Monografia 
(conclusão do curso) - da Universidade Federal de Lavras, Escola de Engenharia Florestal, Lavras.

FONSECA, F. Os efeitos da mineração sobre o meio ambiente. Brasil Mineral, v. 7, p. 74-80, 1989.

FONTES, M. P. F. Estudo pedológico reduz impacto da mineração. Revista Cetesb de Tecnologia Ambiental, São Paulo. v. 5, n. 1, p. 58-61, 1991.

GARDNER, J. Rehabilitación de minas para el mejor uso del terreno: la minería de bauxita en el bosque de jarrah de Australia Occidental. Unasylva, Roma, v. 52, n. 207, p. 3-8, 2001.

GOMES-POMPA, A.; WIECHERS, L. Regeneración de los ecossistemas tropicales y subtropicales. In: GOMES-POMPA, A.; VAZQUEZ-YANEZ, C.; AMO RODRIGUES, $\mathrm{S}$. del et al. (Ed.). Investigaciones sobre la regeneración de selvas altas em Vera Cruz. 2. ed. México: Continental, 1979. p. 11-30.

GOMIDE, F. L. Recuperação de áreas degradadas: a visão do dirigente. In: I SIMPÓSIO SUL - AMERICANO E II SIMPÓSIO NACIONAL DE RECUPERAÇÃO DE ÁREAS DEGRADADAS. Anais... Curitiba. 679 p., 1994.

GRIFFITH, J. J. (1981). Recuperação conservacionista de superfícies mineradas Uma revisão de literatura. Viçosa, S. I. F. Boletim Técnico, n. 2, 51 p.

GUTBERLET, J. Produção industrial e política ambiental: experiências de São Paulo e Minas Gerais. São Paulo: Konrad Adenauer Stiftung, 1996.

HERMANNS, Â. K. Gestão ambiental empresarial: aspectos legais, mercadológicos e econômicos. 2005. Monografia - Universidade Federal de Santa Catarina, Graduação de Ciências Econômicas.

INSTITUTO BRASILEIRO DE MINERAÇÃO - IBRAM. Investimentos em MG. 2008. Disponível em: <http://www.ibram.org.br/>. Acesso em: 12/01/2009.

INSTITUTO BRASILEIRO DO MEIO AMBIENTE E DOS RECURSOS NATURAIS RENOVÁVEIS - IBAMA. Manual de recuperação de áreas degradadas pela mineração: técnicas de revegetação. Brasília: 1990. 95 p.

KAGEYAMA, P. Y.; GANDARA, F. B. Revegetação de áreas ciliares. In: RODRIGUES, R. R.; LEITÃO FILHO, H. F. Matas ciliares: conservação e recuperação. São Paulo: Editora da Universidade de São Paulo: Fapesp, 2001. p. 249287.

KELLER, E. A. Environmental geology, Prentice Hall, EUA, 560 p., 1996.

KOPEZINSKI, I. Mineração x meio Ambiente: considerações legais, principais 
impactos ambientais e seus processos modificadores. Universidade Federal do Rio Grande do Sul. Porto Alegre: Ed. da Universidade, 2000.

LEITE, L. L.; MARTIN, C. R. \& M. H. 1992. Propriedades físico-hídricas do solo de uma cascalheira e de áreas adjacentes com vegetação nativa de campo sujo e cerrado no Parque Nacional de Brasília. p. 392-399. In: Anais do Simpósio Nacional sobre Recuperação de Áreas Degradadas realizado em 25-29 de outubro de 1992 em Curitiba, PR. Universidade Federal do Paraná e Fundação de Pesquisas Florestais do Paraná, Curitiba. $520 \mathrm{p}$.

MAGALHÃES, C. F. Diretrizes para o turismo sustentável em municípios. São Paulo: Roca, 2002.

NAPPO, M. E.; GOMES, L. J.; CHAVES, M. M. F. Reflorestamentos mistos com essências nativas para recomposição de matas ciliares. Boletim Agropecuário da Universidade Federal de Lavras, v. 30, p. 1-31, 1999.

POVIDELO, L. A. \& NETO, R. M. Passivos ambientais em cidades pequenas: uma proposta de recuperação para cava de argila abandonada em Tambaú (SP). Estudos Geográficos: Revista Eletrônica de Geografia, v. 4, n. 2 (2006)

ROSADO, S. C.; SANTOS, M.; ORLANDINI, L. Monitoramento da evolução e auto-sustentabilidade de dunas em reabilitação. Lavras: UFLA/DCF, 1996. 58 p. (Relatório Técnico 1/96).

ROSS, J. L. S. (org.). Geografia do Brasil. São Paulo: Editora da Universidade de São Paulo, 2000. - (Didática; 3).

RUSCHMANN, D. Turismo e planejamento sustentável. Campinas: Papirus, 2005.

SEAKER, E. M.; SOPPER, W. E. Municipal sludge for minespoil reclamation. II: effects on organic matter. Journal of Environmental Quality, v. 17, n. 1, p. 598-602, 1988.

SOBREIRA, F. G., FONSECA, M. A. Impactos físicos e sociais de antigas atividades de mineração em Ouro Preto, Brasil. Revista Geotecnia, n. 92, p. 5-27, 2001

SILVA, G. P. Caracterização química, física e mineralógica de materiais provenientes da mineração de ferro e comportamento de plantas para sua revegetação. 1994. 76 f. Dissertação (Mestrado em Solos e Nutrição de Plantas) Universidade Federal de Viçosa, Viçosa, 1994.

SINDICATO DA INDÚSTRIA MINERAL DO ESTADO DE MINAS GERAIS (SINDIEXTRA). NOTÍCIAS, Minas Gerais 27 abr. 2007. Disponível em: <http://www2.fieng.com.br/sindicatos/sindiextra/notícia/notícia.htm> Acesso em: 16/06/ 2007. 
UNCED. 4th session of the UNCED Preparatory Committee. Promoting Sustainable Agriculture and Development: Land Conservation and Rehabilitation, Chapter 14: 25 pp, 1991.

WAGNER, A. et al. A eleição presidencial e a mineração. Gazeta Mercantil, 20 de setembro de 2002, p. A3.

WILLIANS, D.; BUGIN, A.; REIS, J. L. B. (Coord.) Manual de recuperação de áreas degradadas pela mineração: técnicas de revegetação. Brasília: IBAMA, 1990. 96 p.

Recebido em: 13/01/2009

Aprovado em: 13/02/2009 